Women of Color Faculty Reimagining Institutional Spaces

During the COVID-19 Pandemic

\author{
Patti Duncan ${ }^{1}$, Reshmi Dutt-Ballerstadt ${ }^{2}$, and Marie Lo $^{3}$ \\ ${ }^{1}$ Oregon State University \\ ${ }^{2}$ Linfield University \\ ${ }^{3}$ Portland State University
}




\begin{abstract}
As women of color faculty who have experienced challenges associated with hostile work environments within predominantly white institutions, we consider the ways that working remotely during COVID-19 offers transformative possibilities for reimagining our relationship to the academy. We discuss our embodied responses to institutional spaces that often marginalize faculty of color; how university leadership may be reimagined through a blurring of gendered, racialized lines of "public" and "private" (or institutional and domestic) spaces; and the possibility of healing from the trauma associated with oppressive workplaces and institutional betrayals.
\end{abstract}

Keywords: COVID-19, embodiment, institutional betrayals, institutional politics, leadership, social justice, women of color 


\section{Women of Color Faculty Reimagining Institutional Spaces \\ During the COVID-19 Pandemic}

This collaborative piece emerged from a series of conversations we had during the pandemic, reflecting on our lived experience as women of color faculty working from home during this time. We are engaged in teaching and scholarship that works to challenge multiple forms of oppression within settler colonial, white supremacist, heteronormative institutional settings. We work at three different kinds of academic institutions in Oregon, on the unceded lands of the Cowlitz, Clackamas, Kalapuya, and Yamhill people. Today, the descendants of these people are a part of the Confederated Tribes of the Grand Ronde Community of Oregon and the Confederated Tribes of the Siletz Indians. We are all mothers to young children, and we share the challenges many others are experiencing during this time, including feeling overwhelmed, managing children's remote school while working full time, stress, anxiety, and difficulty focusing. We are also privileged to be employed and able to work from home during COVID-19, and to be tenured faculty members with stable technological support and access to relatively private spaces from which to hold Zoom meetings and online classes.

Previous essays in this journal reflect on the many challenges encountered by women faculty during COVID-19, for example the amplification of structural inequalities, particularly for women faculty with caregiving responsibilities (Baker, 2021); barriers to publishing; and the extra labor of resisting racism and other forms of oppression (Tevis, 2021). However, authors also highlight possibilities, including rethinking academic leadership (Rivera-Mills, 2021) and teaching toward social justice (Cadena, 2021). In this conversation, we follow the thread of possibilities, wondering what we are learning during these difficult months, and how this may fundamentally change our relationships to the academy. In this collaboration we ask, what 
feminist potential or possibilities are enabled by the institutional changes enacted during COVID-19, including working from home, holding classes and meetings online, and other shifts in labor? Our critique of institutional spaces also interrogates how power may be reconfigured in new kinds of remote spaces like Zoom. What innovative spaces or strategies are we creating that we may wish to retain once the pandemic is over? What transformative possibilities might we choose to hold on to?

\section{Embodied Responses to Institutional Spaces}

So many of us who are faculty of color at predominantly white institutions experience physical reactions to hostile work environments. We have discussed a shared experience of bodily discomfort, like knots in the stomach when arriving to campus. Many of us experience embodied responses to spaces replete with the thousand tiny papercuts — or microaggressionsthat structure our experiences in the academy. We consider embodied responses as racialized and gendered, like those discussed by Resmaa Menakem in My Grandmother's Hands: Racialized Trauma and the Pathway to Mending Our Hearts and Bodies, in which he writes that racialized trauma "lives and breathes in our bodies" (2017, p. 5). And M. Jacqui Alexander writes about embodied memory, suggesting that not only violence, but also assimilation can be embodied-"assimilating alienation, one's own as well as others" (2017, p. 277). With heightened visibility of state violence against BIPOC communities, the daily injuries within academic institutions also become more visible and more painful.

Our work as women of color faculty is deeply embodied - how our bodies are seen and treated on our campuses, how we come to represent "diversity" within our institutions, and how we feel, on a physical, somatic level—moving through spaces that are so often hostile to women of color. Sara Ahmed calls this work that so many of us perform "diversity work," the work that 
we do when we're trying to transform institutions, and also the work we do when we do not fit the norms of those institutions (Ahmed, 2017). The experiences we have as "diversity workers" within the academy are often hard to talk about—isolation, fear, racialized harassment, exclusion, affective labor, a lack of mentoring, invisible service, unbearable workloads — some of the effects of racism and sexism and ableism and other forms of oppression that many of us encounter on a daily basis as women of color in the academy. Ahmed describes the brick walls we come up against when we try to change institutions to make them more welcoming to those of us who have often been excluded from and marginalized within them (2017). But, as Sandy Grande argues, struggling for inclusion and recognition within academic institutions also furthers and maintains the power of the state, and sustains settler colonialism (2018). Instead, Grande draws on Audra Simpson's "politics of refusal." We are intrigued by how the shift to remote learning enables us to engage a politics of refusal, particularly to refuse some of the norms of the academy, including its gatekeeping policies and its racialized logic of success and merit and values that renders much of the work we do invisible, or deems it meaningless. Through a shift away from physical spaces of trauma, is it possible to move toward healing, not only for ourselves but also for our students and our larger communities?

\section{"Having a Seat at the Table"}

In the multiple sites of struggle for justice, the language of potential change is sometimes condensed around the image of a conference table around which power has been historically consolidated. Being at this table, as this phrase suggests, means previously marginalized or underrepresented people and perspectives would finally be included and represented and that the circle of white settler heteropatriarchal power might be penetrated and broken. 
When we think of university leadership, this table is a long oval industrial table, covered in dark brown melamine and ringed by plush chairs with arm rests. It is centered in a room with a wall of windows and the ubiquitous decor of books and walnut panels synonymous with academic institutional power. There are two doors on opposite ends of this room, and to enter or exit requires passing by the head of the table.

University offices often draw from the architectural idioms of corporate spaces, and despite recent shifts in the design of the workplace, university office spaces remain stuck in the gendered, hierarchical post-war office spaces that signal male authority through the depersonalization of the office space. Such spaces look different within different kinds of institutions, for example liberal arts colleges, large public universities, land grant institutions, HBCUs, and predominantly white institutions, emerging from various histories in distinct locales. Picturing one of our institutions — a large public university in a predominantly white Pacific Northwest city — we consider the systems of power that shape the spaces in which we work. When we walk into the conference room, the convergence of the spatialization of institutional power and of white patriarchal order, our heart rates are often accelerated. More frequently than not, we have the experience of being the only woman of color in these spaces. Though we may have a seat at the table, we are also acutely aware of how institutional spaces are racialized and gendered, and as we walk past the head of the table, we wonder where we should sit.

The move to remote learning during COVID-19 has changed the spatialization of institutional power organized around the conference table. Meetings on Zoom have remapped the hierarchical ordering of power into a grid, leveled and flattened by the screen where we all visually occupy the same amount of space. While meetings may still be conducted and mediated 
through gendered, racialized leadership figuratively positioned at the head of the table, working from home has also domesticated university leadership by revealing the extent to which the flows and structures of power exert themselves on us through the material and symbolic spatialization of the conference table. No longer buttressed by the infrastructure of white patriarchal power masked by depersonalization, online meetings are re-spatialized and insistently personalized, from the interruptions of children and demanding pets to uneven interest and talent in interior design.

We recognize that systems of privilege and oppression make it easier for some to show their homes than others, coding class status and the privilege of a private workspace. And interruptions of children are frequently associated with the gendered burden of caregiving responsibilities, which may be celebrated for some but scrutinized or judged for others. The disembodiment of online meetings is not necessarily liberating. Yet we read this disembodiment as also a re-embodiment not defined by institutional spaces, showing us some path, however small, outside of the institutional norms that have structured so many of our experiences in the academy. Our working from home is also a form of embodiment that connects us to familial spaces, which may potentially be spaces of empowerment and connection that we had to erase when seated at the table. Now, we can change the view settings from speaker view to grid view or even minimize our screens. We can speak with the camera turned off. While the pandemic has widened racial, economic, and gender disparities, the move online has also revealed the extent to which the struggles for justice, inclusion, equity, and social change necessitate reconfiguring the spatial organization of institutional power.

\section{Limiting Injury: A Move Towards Healing}


For BIPOC academics and particularly women working in highly masculinized, and heteropatriarchal spaces surrounded by “white fragility” (DiAngelo, 2018), experiences of microaggressions are an inescapable everyday reality. Such a reality manifests into invisible bodily harm and injury, fear, fatigue, and anxiety or "cultural taxation" (Padilla, 1994) caused by our obligations and expectations to show good citizenship by serving the diversity missions of our institutions. Taken together, these visceral experiences form the anatomy of what is called "racial trauma" in the academy. Given that most institutional mechanisms are incapable of addressing and redressing the harm and injury caused by racial trauma, many ask this question privately and collectively: will we ever heal?

Sometimes the sites of such trauma are in physical spaces, like the buildings where we work, or in encountering colleagues and administrators who may have harmed us through their complicity with institutional forms of oppression and violence. Then there are those who have actively injured us by their various acts of retaliations, microaggressions, and micro and macro invalidations. Our bodies have witnessed these layered traumas in various rooms or hallways inside concrete and contained buildings, some with windows and others without. This is why our bodies are instantly stressed when entering particular work spaces. Trauma, as Ocean Vuong writes, "affects not only the brain, but the body too, its musculature, joints, and posture" (Vuong, 2019, p. 19).

As the pandemic hit last March and we were all thrown into learning an entirely new mode of engagement via Zoom for both our classes and various meetings, many of us faced a steep learning curve. Yet as months passed, we realized that something has altered, namely, our own relationship to our institutions and some of our colleagues. We no longer have to see them, or pass them in hallways, or plan our exit strategies if we sense they are walking towards us. We 
no longer have those knots in our stomachs, or the anxiety of going to a meeting where we had been the only voice of dissent on a hiring or awards committee defending a BIPOC faculty member or student. Our bodies remember the silent anger transmitted via heavy breathing and stiff postures from those sitting opposite us.

While the pandemic has indeed been devastating in terms of many losses (both lives and livelihoods) it may have also given us an unexpected though complicated gift: a gift of healing by keeping the cameras off to protect oneself from witnessing the memories and sites of trauma; a gift of invisibility while being included on our own terms; a gift of both autonomy and agency from the safe space of "home" where the stomach is no longer in knots. Notions of visibility and invisibility have deep implications for women of color in the US. As Asian American women, we know all too well what it's like to be rendered invisible in contexts of higher education while at the same time frequently being made hypervisible to those in power or to affirm the diversity of institutions or specific programs. In the current political moment, when anti-Asian hate violence has sharply escalated during the COVID-19 pandemic, and hate incidents targeting Asian Americans, particularly Asian American women, have surged by nearly 150 percent, we experience some comfort in the ability to disrupt the binary framework of visibility/invisibility. Turning off a camera while still engaging in a discussion, or shifting to another mode of communication such as chat or text with colleagues during a department meeting offers an intervention, however small, and opens new possibilities for creating solidarity with others outside of normative structures of the academy. Perhaps, the pandemic has opened up possibilities of doing diversity work from the outside rather than inside the university.

\section{Conclusion: Reimagining the Space of the Academy after COVID-19}


In a conversation with Angela Davis, reflecting on sustainable activism in the $21 \mathrm{st}$ century, Grace Lee Boggs said, "the time has come for us to reimagine everything" (POV, 2014). In these challenging times, the idea of reimagining our world offers some hope for transformative justice. So much during these months has felt heavy, difficult, overwhelming. There is a sense of collective grief within our communities, and some days the daily tasks of our work within the university feel impossible. But coming to these conversations with other women of color offers a sense of hope and comradery and the opportunity to imagine new possibilities for refusing former relationships to oppressive institutional spaces. 


\section{References}

Ahmed, S. (2017). Living a feminist life. Duke University Press.

Alexander, M. J. (2005). Pedagogies of crossing: Meditations on feminism, sexual politics, memory, and the sacred. Duke University Press.

Baker, C. (2021). Amplification of Structural Inequalities: Research Sabbaticals During COVID19. The ADVANCE Journal, 2(2).

Cadena, M. L. (2021). Teaching in Times of COVID-19. The ADVANCE Journal, 2(2).

DiAngelo, R. J. (2018). White fragility: Why it's so hard for white people to talk about racism. Beacon Press.

Grande, S. (2018). Refusing the university. In E. Tuck and K. W. Yang (Eds.), Toward what justice? Describing diverse dreams of justice in education (pp. 47-65). Routledge.

Menakem, R. (2017). My grandmother's hands: Racialized trauma and the pathway to mending our hearts and bodies. Central Recovery Press.

Padilla, A.M. (1994). Ethnic Minority Scholars, Research and Mentoring: Current and Future Issues." Educational Researcher, 23(4), 24-27.

POV. American Revolutionary: On Revolution at Berkeley. Excerpts of a conversation between Grace Lee Boggs and Angela Davis, aired June 29, 2014. https://www.pbs.org/video/pov-american-revolutionary-revolution-berkeley/

Rivera-Mills, S. (2021). Leadership in the Time of COVID-19. The ADVANCE Journal, 2(2).

Tevis. T. (2021). By Obligation and By Choice: Taking On Extra Responsibilities During COVID-19 and the Black Lives Matter Movement. The ADVANCE Journal, 2(2). Vuong, O. (2019). On earth we're briefly gorgeous. Penguin. 